\title{
Trauma of Poverty and its Psychological Impact: A Case of Kenya
}

\author{
Elijah Macharia Ndung'u (PhD) \\ Department of Counselling Psychology, Catholic University of Eastern Africa
}

\begin{abstract}
Extreme poverty is a tormenting, dehumanizing and distressing daily phenomenon for the poor and vulnerable in society, which may cause extreme distress to the non-resilient poor hence a predisposing factor to trauma. The study argues that much as poverty and the associated trauma can be explained in economic terms, interventions ought to be more elastic, stretching beyond economic limits and hence, take cognizance of the psychological dimension whose effects and impacts cannot be underestimated. The study assessed how trauma arising from poverty is indeed traumatizing to the poor, marginalized and less resilient poor people in society. The researcher adopted a crosssectional research design and triangulation method (mixes both qualitative and quantitative approach of research). The study areas were Nairobi and Nakuru Counties representative of the urban and rural setting respectively. The study population included social work practitioners, social work clients and key social work informants. The research study covered a total of 141 respondents $(n=141)$. This comprised of 91 social work practitioners, 10 key informants and 40 social work clients. Data collection involved structured and semi-structured questionnaires and interview guides. SPSS (ver. 20 for Windows) was used for data analysis. The key findings of the study were; trauma of poverty was noted as a major issue among the social work clients by social workers and had a high prevalence rate of $64.8 \%$. As such almost all social workers $(94.5 \%)$ were in agreement that addressing trauma of poverty should be given key priority while addressing poverty related issues.
\end{abstract}

Keywords: Trauma, Poverty, Trauma of Poverty, Resilience, Psychological Wellbeing

\section{INTRODUCTION}

$\mathrm{R}$ arely is trauma emanating from poverty seen as a major area of concern, yet the ramifications of poverty to the individual especially the poor and vulnerable in society need not to be overemphasized. As trauma literature reveals, there is a predominant tendency that trauma is viewed as emanating from conventionally perceived causes such as war and terrorism, natural disasters (drought, floods, and earthquakes), accidents, political violence, rape and sexual abuse, alcohol, drug and substance abuse, health issues, death of loved ones among others (Herman,1992; Bracken \& Petty, 1998; Tedeschi, Park \& Calhoun, 1998; Ntomchukwu et al, 1999; Ryle \& Kerr, 2002; Laungani, 2002; Stricker \& Widiger, 2003; Taylor 2006; Kirmayer et al.2007; Covington, 2008;). However, there is another cause of trauma that is rarely given much consideration to. Trauma emanating from poverty is a relatively new aspect towards trauma that has not gained much attention especially from the psychologists, psychiatrist and social workers. Incidentally, trauma of poverty may not be universally recognized as such but is equally traumatizing as other conventionally held causes of trauma. Even though trauma of poverty may be subtler than other forms of trauma (natural disasters or physical assault) its effects, suffered by too many in the country, are no less traumatic nor significant (Bussey \& Wise, 2007).

Trauma arising from poverty is more visible in circumstances where poverty rules supreme over other social problems. It may thus be more eminent in some regions of the world where extreme poverty rates are tremendously high for instance in Sub-Saharan Africa and Southern Asia as compared to other regions in the world. In such countries poverty is a major cause of psychological stress and suffering which torments the poor and helpless individuals with detrimental consequences on their psychological well-being. Most of the affected poor have nowhere to turn for assistance or support and worse still there are ineffective or non-existent mechanisms in these countries to cushion them from such circumstances. Such is the predicament faced by the chronically poor affecting their psychological functionality and hinders their capability to socio-economic development. The affected poor may as well experience severe psychological distress which is a predisposing factor to psychological dysfunction including traumatization. Therefore, the long-term effects of chronic economic struggle coupled with the multi-dimensional aspect of poverty (Manda et al, 2000; Keriga \& Burja, 2009), creates a complex multiple systems interaction that affects psychological wellbeing of individuals (Edin \& Lein, 1997; Friis et al. 2002).

Thus, this paper goes beyond the conventionally known meaning and causes of trauma to define and describe trauma of poverty and its psychological impact on social work clients who are the most vulnerable in society. The complexities and divergent trauma related problems associated with poverty, especially in the African context may be a key predisposing factor to causing trauma of poverty. The study sought to assess the psychological impact of poverty among social work clients. Views were gotten from the social workers helping the social work clients, key informants in social work practice and the social work clients affected by trauma emanating from poverty related issues.

As global literature indicates, there are various definitions to trauma that have been developed and obtaining a common definition to the term is still elusive. Trauma has been investigated from several different theoretical perspectives 
and disciplines, each with its own concepts, meaning, research methodologies, diagnostic nomenclature, therapeutic strategies and outcome measures, thus, it is difficult to have a single one discipline that can solely claim possession of the term and its definition (Laungani, 2002).

In the context of Post-Traumatic Stress Disorder (PTSD), trauma is an extreme traumatic stressor involving direct personal experience of an event that involves actual threatened death or serious injury, or other threat to one's physical integrity (DSM-IV-TR, 2000, p.463). Similarly, James (1989) adds that, trauma is an overwhelming uncontrollable experience that psychologically impacts on victims by creating in them feelings of helplessness, vulnerability, loss of safety and loss of control (Ntomchukwu et al, 1999. p.70). Trauma can also be seen as a socio-political event, a psycho-physiological process, a physical and emotional experience, and a narrative theme in explanations of individual and social suffering (Kirmayer et al., 2007). Hence, traumatic events are regarded as extraordinary stressors by their intensity and tendency to cause helplessness, overwhelming fear, involve threats to life or bodily integrity, and suffering in most people, regardless of personal characteristics (Gutlove \& Thompson, 2003; Covington, 2008; Herman, 1992).

In this paper trauma of poverty is defined as: "Traumatic events, experiences or stressors caused by poverty related issues that threaten the psychosocial wellbeing and or physical integrity of the individual rendering him/her powerless and in a state of hopelessness".

The development of trauma definitions, diagnostic assessment and treatment measurements are more widely applied in the Western world (Laungani, 2002). More so, research on trauma is rather subjective and generally based largely on the nomenclature for PTSD (DeLoach \& Petersen, 2010). Much of the research focuses on the conventionally known causes of trauma (war, political violence, natural disasters, and terrorism), whilst trauma of poverty is rarely given adequate attention despite the evidence of poverty, financial problems and social deprivation being major socio-economic risk factors for mental health problems and disorders (Fryers et al, 2005; Laaksonen et al, 2007 cited in WHO, 2011).

There has been much expression of interest of Western psychologists, psychiatrists and medical professionals to venture into studies on assessing causes, effects, impacts and also interventions to trauma in non-western countries. However, there should be caution towards this endeavor; models developed in Western psychiatry with regard to the effects of trauma should not be exported uncritically to nonwestern societies (Bracken \& Petty, 1998). This is because, favoring Western diagnostic conceptualizations rather than honoring indigenous understandings of trauma further propels the forces of structural oppression, thus silencing African views in deference to Western models (Petersen-Coleman \& Swaroop, 2011).

For one to understand, trauma of poverty then one has to clearly understand the context in which it occurs, since trauma can only be understood and addressed with reference to the specific contexts in which it occurs (Becker, 2004). The diversity of contextual occurrence is very vital to the understanding of the trauma. There are different applications to the term trauma depending on the nature, magnitude and culture where it is applied and may be country specific (Laungani, 2002. Hence, trauma concepts need to be continually reinvented and always contextualized within the specific social reality in which the traumatization occurs (Becker, 2004, p.2).

Even though there seems to be a wide consensus on a general definition to trauma, need to apply it to specific situations is imperative. There is need to broaden the current definition of a traumatic stressor to include experiences that are distressing but not necessarily directly associated with physical threat or injury (Gold et al, 2005). The trauma concept should not only be confined to its clinically Western conventional conceptualization but to also encompass broader aspects of traumatic events and meaning which is culture specific.

Therefore, trauma and its associated interventions ought to be addressed from an intrinsic perspective factoring in the dynamic nature of traumatic events including those arising from poverty. Consequently, it is imperative to have in mind that the description and manifestation of poverty related traumatic experiences encountered in the developing world especially in Sub Saharan Africa where poverty rates are high may not fit that of the Western conceptualization and description. Thus, trauma can be seen as being country and culture specific. Therefore, if one is to wholly grasp the meaning of trauma of poverty in the African context, then one would have to go beyond the conventionally held meaning and description of trauma and a traumatic event.

The PTSD, diagnosis has undergone various modifications over time. For instance, the Diagnostic and Statistical Manual for Mental Disorders-DSM-IV-TR (APA, 2000) categorizes symptoms for PTSD into four main clusters namely; exposure to a traumatic event, re-experiencing intrusive thoughts, avoidance of stimuli associated with the trauma and emotional numbing, and hyper-arousal. In the DSM-V there are more amendments to PTSD including an addition of three symptoms namely; negative expectation of oneself/world /others, distorted blame, and recklessness. It also has four rather than the earlier three symptom groups in DSM-IV-TR (APA, 2013). Table 1 illustrates the diagnostic criterion for PTSD. 
Table 1 : PTSD DSM-IV-TR and DSM V Diagnostic Criterion

\begin{tabular}{|c|c|}
\hline PTSD DSM-IV-TR Diagnostic Criterion & PTSD-DSM V Diagnostic Criterion \\
\hline 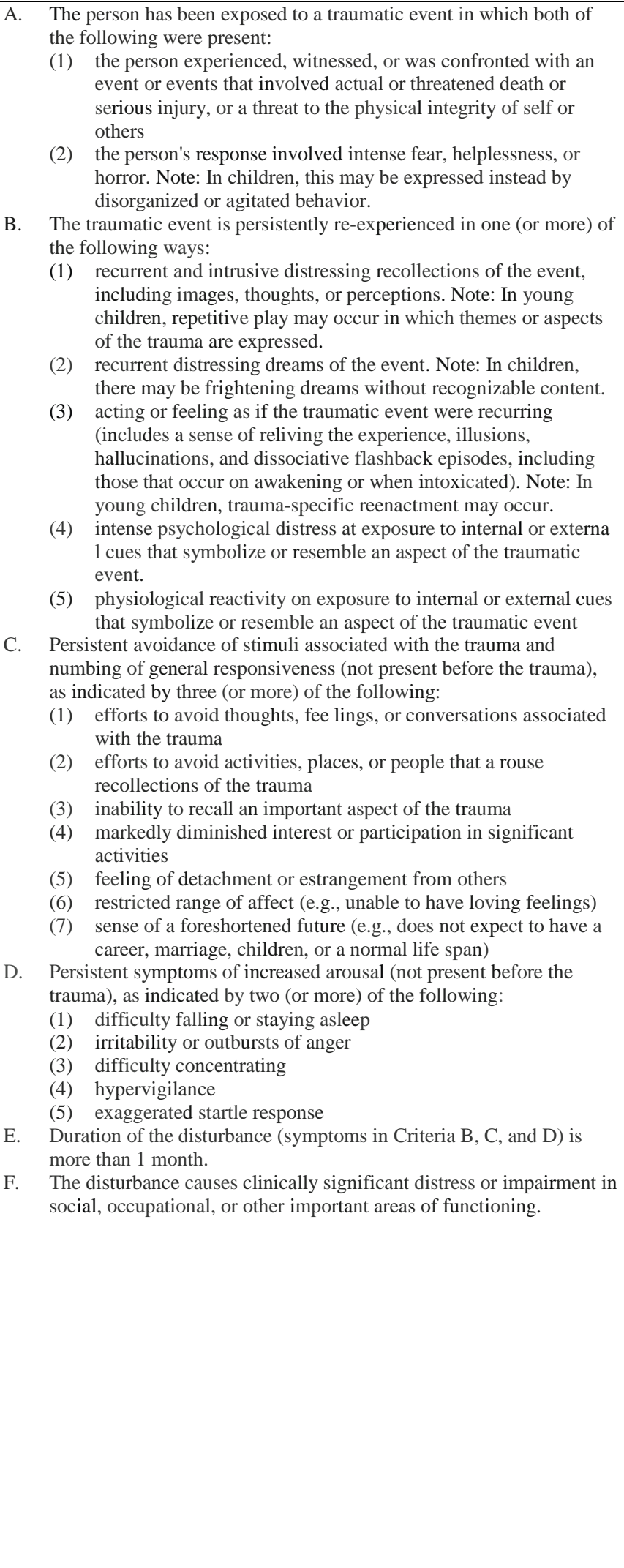 & 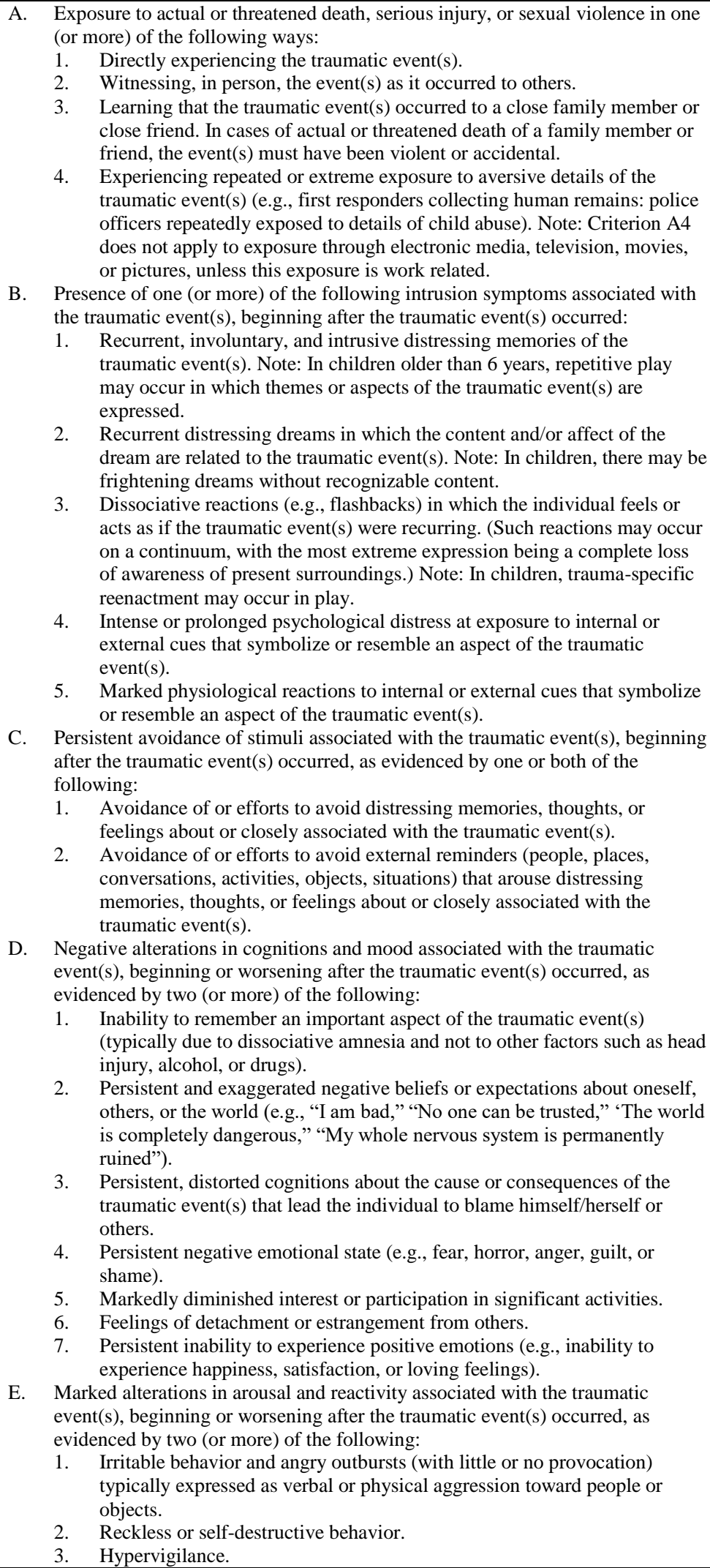 \\
\hline
\end{tabular}




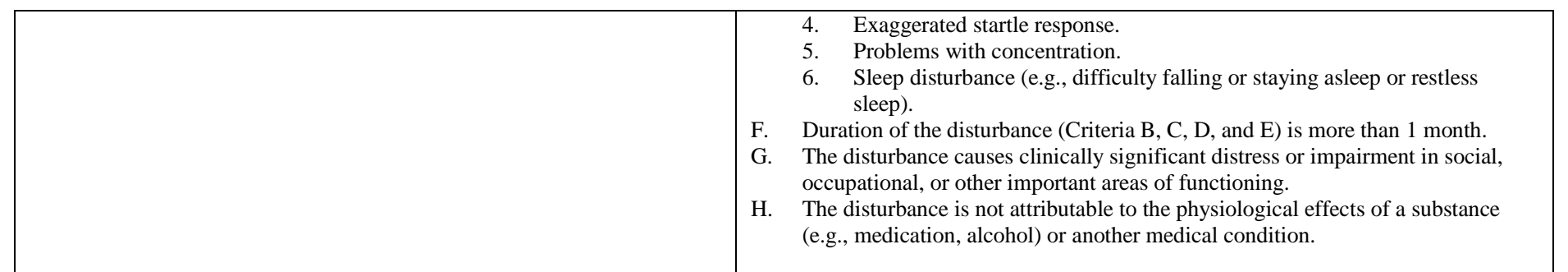

Source: APA, DSM-IV-TR, 2000, pp. 467-468 \& APA, DSM V, 2013, pp.271-272

It is important to note that, although the criterion for assessment of PTSD as indicated by the DSM-IV-TR (APA, 2000) may include some of the major symptoms, it may not be exhaustive enough, not factoring in cultural specific traumatic symptoms and stressors. Thus, trauma emanating from poverty related issues can be contextualized and framed within the PTSD assessment criteria, though in different magnitudes and non-mutually exclusive ways.

Trauma of poverty may not be perceived as 'single blow' traumas such as rape, violent crime, or life threatening accidents but rather as long-term exposure to chronic poverty situations. For instance, the poor and vulnerable especially those in Sub Saharan Africa living in the cyclic poverty trap may endure severe traumatic experiences emanating from extreme poverty and hunger (lack of basic human needs, like food, shelter, clothing, safe drinking water, inaccessibility to basic social and health services), leaving behind an indelible psychological scar affecting their psychosocial wellbeing. These continuous traumatic experiences they are exposed to threaten their psychological functioning and may lead to more severe psychological problems including PTSD. Some of these traumatic experiences occur instantly, or in certain instances, may remain repressed in one's psychic system for several months and even years, before emerging to the surface of one's consciousness, as PTSD (Laungani, 2002).

Traumatic events are part and passel of our existence, they are inevitably escapable. More so, James \& Gilliland (2001) acknowledge that, during the course of a lifetime all people experience a variety of personal traumas, such as divorce or illness, and many others will also live through cataclysmic events, like natural disasters or experiencing acts of violence which are catastrophic (cited in Stricker \& Widiger, 2003, p.431).

In addition, Edin \& Lein (1997) and Friis, Lieb, Pfister \& Wittchen (2002) argue that, those living in poverty are predisposed to stress resulting to deviant behaviors such as teen pregnancy, crime, substance abuse, chronic addiction and may cause health problems (cited in Hawkins \& Kim, 2011). They further state that, poverty and economic struggle have a psychological impact that works in a cyclical way. The longterm effects of chronic economic struggle coupled with the multi-dimensional aspect of poverty (Manda et al, 2000; Keriga \& Burja, 2009), suggest that there is a complex multiple systems interaction that affects psychological wellbeing of individuals (Edin \& Lein ,1997; Friis et al. 2002).
To have a closer glimpse of how poverty can be devastating to the psychological wellbeing of individuals, one can look at a study conducted by Kjeill Underlid (2007) a Norwegian psychologist who set out to study the "subjective meaning of relative poverty in affluent welfare states as experienced by the poor themselves" (cited in Anand \& Lea 2011, p.285). He explored the mental dimensions of poverty in particular feelings of insecurity to examine people's experience of unsatisfied needs including unsatisfied psychological needs which he saw as deep-seated, general, continuous and widespread urges, desires or wants that may be more or less conscious/unconscious. Underlid's study clearly indicates that poverty can create feelings of distress, anxiety and insecurity that may impede the individuals to attain their full functionality. He also notes that feelings of anger, sadness, frustration, devalued self-images, social devaluation, shame and loss of autonomy may be key aspects of the experience of poverty (Anand \& Lea 2011).

Goldestein (1973) argues that, stress can occur when there is a wide gap between an individual's achievements and their ambitions, a situation that is familiar to those living in poverty (cited in Turner \& Lehning, 2006), which is also a prevalent feature among the poor and vulnerable in Kenya. Similarly, in a study conducted by Ssebunnya et al (2009) on Stakeholders Perceptions of Mental Health Stigma and Poverty in Uganda indicates that, poverty was reported to be a major cause of distress with potential for significant mental health problems, as many poor and unemployed people especially the uneducated result to alcohol and other illicit drugs to cope with their frustrations, thus making them susceptible to mental health problems. This indicates that, poverty as a risk factor for mental health issues and more so psychological problems are inevitably a cause for alarm in the Sub-Saharan Africa region.

Poverty deprives of the individual's freedom, dignity, selfesteem and capability to live a healthy decent standard of livelihood, and the denial of opportunities for living a tolerable life (Sen, 1999; UNDP, 1997). Life can be prematurely shortened. It can be made difficult, painful or hazardous (UNDP, 2011, p. 5). Poverty is highly stigmatizing, isolating and damaging with severe effects on people's lives (Wilkinson \& Pickett, 2009; Ridge, 2009 cited in Batty \& Flint, 2010). It hampers the affected individuals' actualization of their full potential, hinders psychosocial and economic progress and is inevitably deterrence to social development. Consequently, the concomitant effects of such deprivations in 
addition to the long-term vicious cycle of chronic poverty gravely undermines the affected poor individual's resilience with detrimental effects to their psychosocial well-being.

Bussey \& Wise (2007) have conceptualized poverty in terms of its psychological impact on the individual. They argue that, poverty as social trauma is an important perspective that should not be underestimated. Likewise, poverty and economic struggle have a psychological impact that works in a cyclical way (Edin \& Lein, 1997: Friis et al., 2002 cited in Hawkins \& Kim, 2011) and may lead to mental health disorders exhibited through pathways such as stress or deprivation (Johnson, Cohen, Dohrenwend, Link, \& Brook, 1999; Miech, Caspi, Moffitt, Wright, \& Silva, 1999 cited in Das et al, 2007. p. 468).

Although there seems to be a general consensus among psychiatrists, mental health practitioners, psychologists and social workers on a significant relationship between poverty and mental health, especially on mental disorders (Patel \& Kleinman, 2003; Bradshaw et al,2004; Miranda \& Patel ,2005;Anand \& Lea ,2011;WHO,2011; Yoshikawa et al, 2012; Jenkins et al, 2012; Lund, 2012), little attention has been given towards trauma of poverty, yet the significant consequences of poverty including distress, helplessness, threatened physical integrity and psychological impairment of the individual are well too known.

Trauma emanating from poverty has not received much attention in recent years and may not be seen as a major area of concern, yet the psychological ramifications of poverty on the poor and vulnerable in society are dire and need not to be overemphasized. For instance, as people find themselves in the center of compression by income poverty, inability to access and/or afford services, absence of social protection systems, social class stratification, structural violence, amid weakening traditional support systems and heightening individualistic tendencies, such people get to a point when they feel nothing seems to make a difference. This straining and stressful cyclic poverty trap which many poor individuals find themselves in weakens their coping mechanism and may as well result to psychological dysfunction including traumatization. Though, some individuals with strong resilient capabilities may be able to persevere and with stand the existing circumstances, hence surviving regressing into trauma. However, the non-resilient poor trapped in the vicious cycle of chronic poverty become overwhelmed with the prevailing circumstances succumbing to a state of helplessness with nowhere to run or anyone to turn to resulting to extreme distress, frustration, depression, hopelessness and traumatization. Such conditions render them helpless, and as human beings we cannot tolerate helplessness; it is against our instinct for survival (Bloom, 1999, p. 3). For example, the cognitive impact exhibited by living in poverty is well illustrated by a man from Guinea Bissau;
When I don't have [any food to bring my family] I borrow, mainly from neighbors and friends. I feel ashamed standing before my children when I have nothing to help feed my family. I' $m$ not well when I have nothing to help feed my family. I'm not well when I'm unemployed. It is terrible (Narayan et al, 2000 cited in Patel \& Kleinman, 2003, p.611).

Such precarious situations due to living in the vicious cycle of chronic poverty results to extreme distress, frustration and helplessness among the non-resilient poor individuals; they find themselves in a state of dispiritedness and having lost their nerve, energy and liveliness (Wilson, 2004).

The multifaceted web of poverty exemplified by unemployment, low wages, lack of markets for the little and/or poor produce, low commodity prices, lack of supportive production and marketing institutions, lack of access to credit, inaccessibility to health services, drought, floods, human wildlife conflict and deforestation (GoK, 2007 \& 2001; Ndiku, 2007, p. 159; Nafula et al, 2005) and absence of meaningful social protection, among other things leave many chronically poor Africans with limited or no alternatives. The resultant myriad of potential stressors of trauma that emanate from poverty affect thousands if not millions of people, and may be equated to being the single most detrimental cause of various traumatic experiences in Sub-Saharan Africa. This poses tremendous challenges and is a big threat to the psychological wellbeing of the poor and vulnerable in addition to being a predisposing factor to mental health issues including trauma.

The non-resilient individuals unable to cope with the tormenting and distressing experiences resultant from chronic poverty are more at risk of being severely affected psychologically and may end up being traumatized. The nonresilient individuals may become more easily paralyzed or isolated rendering them helpless (Herman (1992). Therefore, the non-resilient individuals become more at risk of being traumatized since both their internal and external resources are inadequate to cope with external threat (Van der Kolk, 1989 cited in Bloom, 1999. p.2). Consequently, the risk of developing more psychological complications later is imminent including impairment from their normal functioning and may eventually lead to developing PTSD (Ryle \& Kerr, 2002, p.145).

\section{METHODOLOGY}

The study used a cross-sectional research design, in order to assess trauma of poverty from a cross-section of the population (social workers, key social work informants and clients from Nairobi and Nakuru counties). The study adopted a triangulation method which mixed both qualitative and quantitative approach of research. The choice was informed by the fact that, this method is used by researchers in comparing quantitative results with qualitative findings to attain valid and well substantiated conclusions about a single phenomenon (Creswell \& Clark, 2007, p.65). The population 
under study included respondents from Nairobi and Nakuru Counties; these were social workers, social work clients and key informants in the social work profession.

The target population was 200 social work practitioners, 10 key social work informants and 40 social work clients $(100$ from Nairobi and Nakuru County). Simple random sampling was used to get the actual sample size of 100 social work practitioners (50 from each county). Non-probability sampling method (purposive sampling) was applied to get the 10 key social work informants and 40 social work clients from Nairobi and Nakuru counties. Total sample size was 150 respondents. However, 91 questionnaires were received at the end of the data collection process fully filled. Hence, the actual respondents were 141 respondents $(n=141)$. This comprised of 91 social work practitioners, 10 key informants and 40 social work clients from Nairobi and Nakuru counties. Table 2 shows the sample distribution of respondents. Structured and semi-structured questionnaires, and interview guides were used for the study. Quantitative data was analyzed using Statistical Package for Social Sciences (SPSS) version 20 for Windows and Qualitative data using content analysis through thematization process.

Table 2: Sample distribution of respondents

\begin{tabular}{|c|c|c|}
\hline $\begin{array}{c}\text { Type of } \\
\text { respondent }\end{array}$ & $\begin{array}{c}\text { Sample } \\
\text { size }\end{array}$ & Number of respondents interviewed \\
\hline $\begin{array}{c}\text { Social work } \\
\text { practitioners }\end{array}$ & 100 & 91 (Nairobi and Nakuru county) \\
\hline Key informants & 10 & 10 (Nairobi and Nakuru county) \\
\hline $\begin{array}{c}\text { Social work } \\
\text { clients }\end{array}$ & 40 & $\begin{array}{c}40 \text { (4 FGDs }-2 \text { from Nairobi and } \\
\text { Nakuru county, comprising 10 clients } \\
\text { each) }\end{array}$ \\
\hline Total & $\mathbf{1 5 0}$ & $\mathbf{1 4 1}$ \\
\hline
\end{tabular}

III.

FINDINGS AND DISCUSSION

Trauma of poverty as a major problem among social work clients

Trauma of poverty is well understood by those affected most by it, who include the poor and marginalized in society. The study sought to assess this aspect of trauma of poverty from the social work practitioners and social work clients. From the findings, the social workers and social work clients interviewed had a good understanding of the trauma concept, they generally defined trauma of poverty as:-

- The effect of extreme levels of poverty over long periods resulting to helplessness and extreme distress.

- Emotional disability or mental restlessness due to lack of basic needs propelled by chronic poverty causing extreme distress and psychological problems.

The research study sought to assess the prevalence of trauma of poverty among the social work clients. The research findings indicate that the prevalence rate of trauma of poverty among social work clients was high with $64.8 \%$ of the social work practitioners affirming this, $31.9 \%$ said it was moderate while $2.2 \%$ noted it was low. Figure 1 shows the findings.

Figure: 1 Prevalence rate of trauma of poverty among social work clients

Prevalence rate of trauma of poverty among social work clients

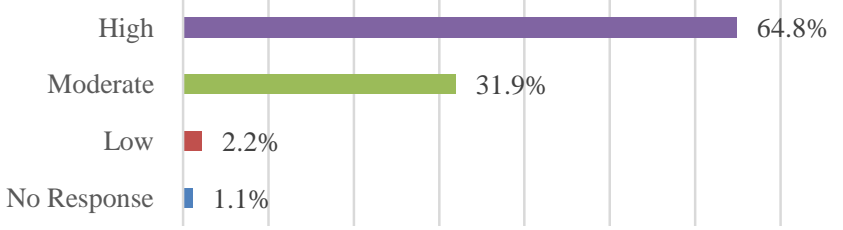

$0.00 \% 10.00 \% 20.00 \% 30.00 \% 40.00 \% 50.00 \% 60.00 \% 70.00 \%$

No Response $\square$ Low $\square$ Moderate $\quad$ High

The findings in figure 1 confirm that, indeed trauma of poverty is a major issue of concern among the social work clients and also has a high prevalence rate. There was a general consensus from the social work practitioners interviewed on some of the main reasons for the high prevalence of trauma of poverty. They indicated that; extreme poverty leads to incapacitation among the poor in society, whereby one is unable to fend for him/herself or the family and this may cause extreme distress to the individual. This is similarly supported by Sen (1999) and UNDP (1997) whereby, poverty deprives of the individual's basic capabilities, freedom, dignity, self esteem and capability to live a healthy decent standard of livelihood. For instance, the social work practitioners noted that;-

Lack of basic needs leads to clients being vulnerable to trauma of poverty e.g many clients are psychologically affected because they are not able to meet their needs especially food, payment of rent and school fees (Social Work Practitioner, R22). Most poor people especially parents get traumatized when they cannot provide for basic needs of their children and families. A traumatized caregiver/parent cannot think straight and end up developing some behaviors that affect other society members indirectly like engaging into alcoholism, drug abuse or prostitution (Social Work Practitioner, R73).

Such desperation pushes some of the clients into risky behaviors in order to get some money to support themselves and their families. For example one social worker noted;-

High risk behaviors like prostitution and drug abuse expose the clients to vulnerability to HIV/AIDs thus leading to trauma. Commercial sex workers engage in such activities due to unemployment and hence see it as a quick way to earn money (Social Work Practitioner, R25). 
It is such traumatic stressors as described above that inflict severe psychological torment on the poor and vulnerable in society with weak resilience capabilities, hence developing feelings of powerlessness, hopelessness, anger, depression and low-self esteem. Hence, trauma of poverty is a real problem that is affecting the poor and marginalized people in society with detrimental consequences on their psychological wellbeing. The above findings correspond with those of Underlid (2007) on how relative poverty psychologically affects the poor individuals living in affluent (cited in Anand \& Lea 2011, p.285). He noted that feelings like, social devaluation, loss of autonomy, devalued self-images, anger, shame, guilt and sadness may be core facets of the experience of poverty (Anand \& Lea 2011). And as described by the Diathesis Stress Theory (Blueler, 1963; Rosenthal, 1963 cited in Ingram \& Luxton, 2005), it is such pre-dispositional stressors that weaken the people's resilience against stressful circumstances as those caused by poverty and may lead to development of severe psychological problems including trauma.

\section{Psychological effect of trauma of poverty among social work clients}

In terms of the effects that trauma of poverty has on the individual, it was well exemplified by the social work clients giving their experiences of distress due to extreme poverty. For instance, one client from Nairobi County noted; -

I have problems in supporting my own children and for my sister who are orphans. It distresses me so much. I think poverty makes one traumatized and distressed (Social work Clients, FGD).

Another from Nakuru County had this to say; "sometimes we skip meals due to lack of money". In general it was clear from the clients perspective that, extreme distress (trauma) caused by poverty makes one become helpless and hopeless (there is no hope for living). This may lead the individual to engage in other deviant behaviours like alcoholism, drug abuse, prostitution and even suicidal ideation in an effort to escape from such distress. Thus there is need especially for the social work practitioners to urgently address it.

In assessing the psychological impact of trauma of poverty, the researcher asked the social work clients to give factors that contribute to extreme distress due to poverty in their lives that may lead to trauma. Some of the major issues given were;lack of adequate food for my family, lack of descent clothing, poor health due to inaccessible medical services, discrimination from society due to poverty, lack of support from relatives and family members, lack of finances to sustain my family due to unemployment, lack of school fees to educate my children leading to school dropout, teenage pregnancies due to engagement into drugs and substance abuse, alcoholism and prostitution as a substitute to earn a living among the youth.

Consequently, such situations as indicated above contribute to the chronic cycle of poverty that affects the non-resilient individuals. These individuals look for an escape from such devastating situations by engaging in socially inappropriate and mal-adaptive activities and bevarioural tendencies. Due to hopelessness, some engage in risky deviant behaviors and end up suffering slowly not realizing the dangers they expose themselves to including psychological and health problems. In support of the issues social work clients go through, social workers noted that; -

The clients I deal with are mostly from the slums and are traumatized as a result of lack of basic amenities, though they are in denial. This is normally identified during the counseling sessions (Social Work Practitioner, R35). Most of the clients who have being traumatized by poverty usually exhibit behavioral problems and are socially and emotionally not well adjusted which affects their ability to come to terms with life, some end up committing suicide if not well counseled (Social Work Practitioner, R7). Poverty leads to trauma making the person incapacitated. Trauma pre-disposes them to other challenges such as illiteracy, unemployment, helplessness among others hence making clients vulnerable and susceptible to other social problems (Social Work Practitioner, R50).

Such issues faced by the social work clients are indeed predisposing factors to trauma and may lead to psychological dysfunction of the individuals affected, hampering their socioeconomic capabilities for a stable and decent livelihood. For instance, some of the social work practitioners observed that; -

During the period when one is traumatized one cannot think clear, make concrete choices, feels stigmatized have low self-esteem which should first be addressed (Social Work Practitioner, R5). Many people especially the poor suffer from trauma without really knowing until it takes a toll on their daily life (Social Work Practitioner, R62). Similarly, it was noted that;- Trauma causes people not to realize their full potential and their capabilities. If trauma of poverty is addressed most of those suffering from it will be made to accept their situation and empowering them will be much easier and sustainable (Social Work Practitioner, R35).

In an attempt to escape from the chronic cyclic poverty trap, the social work clients at times use strategies that are risky, detested, result from no better options and traumatizing in nature. For instance, many poor Africans with limited alternatives resort to; alcoholism, commercial sex work, early marriages and teenage pregnancies, withdrawing children from school, child labor to supplement household income, child trafficking, drug trafficking and abuse. Due to high levels of unemployment especially among the youth, they end up falling prey to other socially mal-adaptive practices and behaviors engaging in easy but dangerous avenues for sustainability such as drug and substance trade and abuse, 
alcoholism, and prostitution among others (Hawkins \& Kim, 2011; Ssebunnya et al, 2009; Gutlove \& Thompson, 2003).

The conspicuous consequences of poverty impel the poor to extremities in their lives with detrimental psychological and health issues and may result to traumatization. Such experiences as a result of poverty related problems may result to very traumatic events affecting every part of a person's being, thoughts, emotions, behaviors and physical reactions (Sonderup, 1996, p. 13 cited in Ntomchukwu et al 1999 p.70). The situation of living in chronic poverty results to a continuous process of traumatic stressors inflicting psychological pain among the affected poor. This in turn results to sequential traumatization as described by Hans Keilson, trauma is a continuous process that develops even after the specific traumatic event is past; hence, trauma is a process, which develops sequentially (Becker, 2004, p.6). This is as the result of the sequence of individual incidents the poor endure due to the long-term vicious cycle of chronic poverty leading to eventual breakdown of the individual's coping capabilities and resilience resulting to traumatization. These tormenting experiences the poor endure as a result of extreme poverty hamper the attainment of their full potentiality and self-actualization in life and deprive them off opportunities to engage in meaningful economic activities and ultimately is an impediment to social development.

\section{Differences between Women and Men in Relation to Trauma of Poverty}

The research findings indicated that women do suffer more than men due to trauma of poverty. Figure 2 shows the illustration that women are more prone to trauma of poverty the men. Majority $(91.2 \%)$ of the social work practitioners noted that women are more affected differently by trauma of poverty than men while only $6.6 \%$ said they are not.

Figure 2: Differences among women and men being affected by trauma of poverty

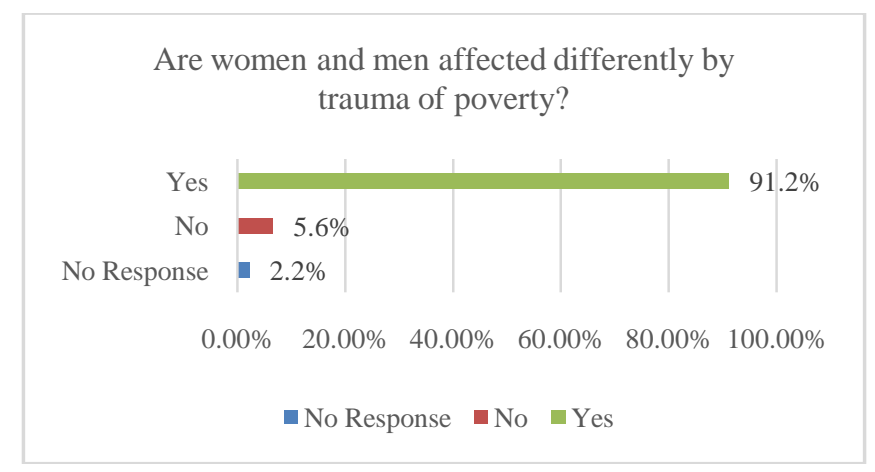

From the FGD discussions with social work clients, it came out strongly that, women do suffer more than men because men do not care of the issues in the house; they brush them away and avoid or neglect their responsibilities as heads of the family. For instance, one client respondent noted; "most men nowadays want to be married and stay comfortable. They want to marry women who are more financially stable"
(Social Work Clients FGD). They also noted that women are left with the heaviest burden to fend for the children. One client noted; - "A woman may not abandon her children but a man may easily marry another woman and abandon the first wife and children" (Social Work Clients FGD). One social work practitioner noted that; "women are more overwhelmed and show signs of hopelessness than men who tend to hang on to their power/strength of being a man ((Social Work Practitioner, R35)". The above illustrates the women's endurance, determination and will power to take care of their families regardless of whatever circumstance they are in. The women try effortless to keep their house in order and provide for their children however best they can. For example, one client said; "mama mwerevu hujenga nyumba yake, mjinga huibomoa" - a wise woman builds her houselfamily but a foolish one destroys it" (Social Work Clients FGD). From the above it is clear on the different symptomatic signs and behaviors exhibited in men and women suffering from trauma emanating from poverty related issues. Therefore, as clearly indicated women suffer more than men and have differentiated characteristic behavior from the men.

Extreme poverty elicits feelings of frustration, hopelessness and emotional distress which are feasible stressors that may cause trauma among the chronically poor and vulnerable in society. The poor have immense challenges as a direct result from poverty, especially so in situations where the gap between an individual's achievements and their ambitions is very wide, a situation that is familiar to those living in poverty (Goldestein, 1973 cited in Turner \& Lehning, 2006). This is a prevalent feature among the poor in the developing world especially in Sub Saharan Africa. It is no wonder that the psychological impact of those living in poverty is characterized by feelings of shame, stigma and humiliation (Narayan et al 2000 cited in Patel \& Kleinman (2003, p. 611). Such environments the non-resilient poor get entangled may as well be predisposing factors to trauma of poverty. Consequently, trauma develops as a continuous stress of extreme intensity, resultant from the permanent situation of vital threat that reigns in the social fabric (Madariaga, 2002, p.5). Therefore, the state of hopelessness the non-resilient poor find themselves in exacerbated by chronic poverty which is a scenario eminent in Sub-Saharan Africa and is a predisposing risk factor for trauma of poverty.

\section{CONCLUSION}

The dehumanizing and distressing phenomenon the poor trapped in the long-term vicious cycle of chronic poverty inevitably causes traumatic stressors inducing severe psychological torment on the non-resilient individuals. These tormenting experiences result to development of negative psychological repercussions including feelings of powerlessness, hopelessness, helplessness, low-self-esteem, depression and traumatization. Therefore, it is imperative that social scientists take cognizance of the psychological dimension of poverty whose affect and impact has severe 
psychological consequences on the individual and robs him/her the opportunity to a decent meaningful livelihood.

Even though the impact of trauma seems to be universal on a biological expression both attribution and conceptualization of traumatic experiences are culture based (Drozdek \& Wilson, 2007, p.381). Therefore, conceptualization and manifestation of trauma is indeed culture and regional specific. What may be traumatic in one community may not be to another, thus there is need to understand the diverse nature and manifestation of trauma other than the conventionally perceived and recognized causes of traumatic experiences. There is need to incorporate other diverse culture specific traumatic stressors like extreme poverty which afflicts majority of the chronically poor with detrimental psychological consequences, especially in the developing world including Sub Saharan Africa where poverty rates are still extremely high.

The need to have a broader conceptualization of the trauma concept is now more necessary than ever due to the multidimensionality of poverty and its associated problems which cause havoc on the psychological wellbeing of the poor in society. Hence, a continuous reinvention and contextualization of the trauma concept within its specific social reality where the traumatization occurs is inevitable (Becker, 2004). The conceptualization of the trauma concept needs a reevaluation to include the broader intricate aspects of traumatic events and meaning which is culture specific. Thus trauma of poverty should be considered as equally traumatizing as the clinically perceived Western conventional causes of trauma. Perhaps it is time psychologists, psychiatrists and social workers take cognizance of the imminence of trauma emanating from poverty in addition to the well-known conventional causes of trauma. Research into trauma of poverty discourse needs to be given consideration due to the dynamism of poverty in the $21^{\text {st }}$ Century. Trauma is culture specific and needs to be understood within the different contexts it occurs. Hence, it is only appropriate to give significant attention to trauma of poverty due to its enormity and detrimental psychological consequences among the chronically poor and non-resilient in society especially in regions where poverty rates are still extremely high. In order to effectively alleviate poverty and attain sustainable social development, it is only prudent to tackle poverty from its multidimensional facets including addressing trauma of poverty.

\section{REFERENCES}

[1] American Psychiatric Association. (2013). Diagnostic and statistical manual of mental Disorders, $\left(5^{\text {th }}\right.$ ed.). Washington, DC: Author

[2] American Psychiatric Association. (2000). Diagnostic and statistical manual of mental disorders, ( $4^{\text {th }}$ text revised edition). Washington DC: Author

[3] Anand, P. \& Lea, S. (2011). The psychology and behavioural economics of poverty. Journal of Economic Psychology,32(2), 284-293
[4] Batty, E. \& Flint, J. (2010). Self-esteem, comparative poverty and neighbourhoods. Research paper No. 7. Centre for regional economic and social research: Sheffield Hallam University

[5] Becker, D. (2004). Dealing with the consequences of organised violence in trauma work. (Edited version, August 2004. $1^{\text {st }}$ launch January 2001). Berghof research center for constructive conflict management. Retrieved from http://www.berghof-handbook.net

[6] Bloom, S. L. (1999). Trauma theory abbreviated. Retrieved from http://www.dhs.vic.gov.au/_data/assets/pdf_file/0005/587966/tra uma_theory_abbreviated_sandra_bloom.pdf

[7] Bracken, P.J. \& Petty, C. (Eds.). (1998). Rethinking the trauma of war. London: Free Association Books

[8] Bradshaw, J., Kemp, P., Baldwin, S. \& Rowe, A. (2004). The drivers of social exclusion:A review of the literature for the social exclusion unit in the breaking the cycle series. London: Crown

[9] Bussy, M. \&Wise J. B. (Eds.). (2007).Trauma transformed: An empowerment response.Empowering the powerless, a social work series. New York: Columbia University Press

[10] Covington, S. S. (2008).Women and addiction: A trauma-informed approach journal of psychoactive drugs, SARC supplement 5. Retrieved http://www.stephaniecovington.com/pdfs/CovingtonSARC5.pdf

[11] Creswell, J. W. \& Clark P.V. L. (2007). Designing and conducting mixed methods research.Thousand Oaks, CA: Sage Publications

[12] Das, J_, Do,. Q.T, Friedman, J., McKenzie, D., \& Scott, K. (2007). Mental health and poverty in developing countries: Revisiting the relationship .Social Science \& Medicine 65 (2007) 467-480

[13] DeLoach, C., \& Petersen, M. (2010). African spiritual methods of healing: The use of candomble' in traumatic response. Journal of Pan African Studies, 3(8), 40-65

[14] Drozdek, B. \& Wilson, J.P. (Eds.). (2007). Voices of trauma: Treating psychological trauma across cultures. New York: Springer Science Publishers

[15] Edin, K., \& Lein, L. (1997). Making ends meet. New York: Russell Sage Friis, R. H, Wittchen, H. U, Pfister, H, \& Lieb, R. (2002). Life events and changes in the course of depression in young adults. European Psychiatry, 17(5), 241-253

[16] Gold, S.D., Marx, B.P, Soler-Baillo, J.M. \& Sloan, D.M. (2005). Is life more traumatic than traumatic stress? Journal of Anxiety Disorders 19(6), 687-698

[17] Government of Kenya. (2007). Basic report of fourth participatory poverty assessment report (PPA-IV). Nairobi: Government Printer

[18] Government of Kenya, (2001). Poverty reduction strategy paper 2001. Nairobi. Government Printer.

[19] Gutlove, P. \& Thompson, G. (2003). Psychosocial healing: A guide for practitioners. Massachusetts: Institute for Resource and Security Studies Cambridge.

[20] Hawkins, R.L. \& Kim, E.J. (2011). The socio-economic empowerment assessment: addressing poverty and economic distress in clients. Clinical Social Work Journal, 40(1), 194-202

[21] Herman, J. L. (1992). Trauma and recovery. New York: Basic Books Ingram, R. E., \& Luxton, D.D. (2005). Vulnerability-stress models. In B.L. Hankin \& J.R.Z. Abela (Eds.), Development of psychopathology: A vulnerability-stress perspective (pp. 32-46). Thousand Oaks, CA: Sage Publications

[22] Jenkins, R., Njenga, F., Okonji, M., Kigamwa, P., Baraza, M., Ayuyo, J., ... Kiima, D. (2012). Prevalence of common mental disorders in a rural district of Kenya, and socio-demographic risk factors. International Journal of Environment, Research and Public Health, 9(5), 1810-1819

[23] Keriga, L. \& Bujra, A. (2009) Social policy, development and governance in Kenya. A profile on healthcare provision in Kenya. Nairobi: Development Policy Management Forum (DPMF)

[24] Kirmayer, L.J, Lemelson, R. \& Barad M. (Eds.) (2007). Understanding trauma: Integrating biological, clinical and cultural perspectives. New York: Cambridge University Press

[25] Laungani, P. (2002) Stress, Trauma, and coping strategies: Crosscultural variations. International Journal of Group Tensions, $31(2), 127-154$

[26] Lund, C. (2012). Poverty and mental health: A review of practice and policies. Neuropsychiatry, 2(3), 213-219 
[27] Madariaga, C. (2002). Psychosocial trauma, post- traumatic stress disorder and torture. Retrieved from http://www.cintras.org/textos/monografias/monog_trauma_psicoso cial_ingles.pdf

[28] Manda, D. K., Kimenyi, S. M. \& Mwabu, G. (2000). A review of poverty and antipoverty initiatives in Kenya. Nairobi: Kenya Institute for Public Policy Research and Analysis (KIPPRA)

[29] Miranda, J.J. \& Patel, V. (2005). Achieving the millennium development goals: Does mental health play a role? PLoS Medicine, 2(10), e291. doi:10.1371/journal.pmed.0020291

[30] Nafula, N. N., Onsomu, E. N., Mwabu, G.\& Muiruri, S. (2005) Review of policy options for poverty reduction in Kenya. Nairobi: Kenya Institute for Public Policy Research and Analysis (KIPPRA)

[31] Ndiku, J. M. (2007). The issue of poverty in the provision of quality education in Kenyan secondary schools. Educational Research and Review, 2(7), 157-164

[32] Ntomchukwu, M.S, Kakubeire,B.P \& Pritz, A. (Eds.). (1999). Cross-cultural dialogue on psychotherapy in Africa. South Africa: The University of the North Press

[33] Patel, V. \& Kleinman, A. (2003). Poverty and common mental disorders in developing countries. Bulletin of the World Health Organization, 81, 609-615

[34] Petersen-Coleman, M. N. \& Swaroop, S. R. (2011). Complex trauma. A critical analysis of the Rwandan fight for liberation. The Journal of Pan African Studies, 4(3), 1-19

[35] Ryle, A. \& Kerr I.B. (2002). Introducing cognitive analytic therapy: Principles and practice. New York: John Wiley \& Sons Ltd

[36] Sen, A. K. (1999). Development as freedom. New York: Oxford University Press Ssebunnya, J. , Kigozi, F., Lund, C., Kizza, D. \& Okello, E. (2009). Stakeholder perceptions of mental health stigma and poverty in Uganda. BioMed Central International Health and Human Rights, 9(5)

[37] Stricker, G. \& Widiger, T. A. (Eds.). (2003). Handbook of psychology. Clinical psychology. (Vol.8). Hoboken New Jersey: John Wiley \& Sons Inc

[38] Taylor, S. (2006). Clinician's guide to treating PTSD: A cognitivebehavioral approach. In R. G. Tedeschi, C. L. Park, \& L. G. Calhoun (Eds.). (1998). Posttraumatic growth: positive changes in the aftermath of crisis. Mahwah: New Jersey. Erlbaum

[39] Tedeschi, R. G., Park, C. L., \& Calhoun, L. G. (Eds.). (1998). Posttraumatic growth: positive changes in the aftermath of crisis. Mahwah, New Jersey. Erlbaum.

[40] Turner, K. \& Lehning, A. (2004) Psychological theories of poverty. In M.J. Austin, (2006). Understanding Poverty from multiple social science perspectives: A learning resource for staff development in social service agencies. Retrieved from http://cssr.berkeley.edu/bassc/public/CompletePovertyReport0823 06.pdf

[41] United Nations Development Programme. (2011) Human development report 2011. Sustainability and equity: A better future for all. New York: United Nations

[42] United Nations Development Programme. (1997). Human development report 1997. New York: Oxford University Press

[43] Wilson, J.P., \& Drozdek, B. (Eds.). (2004). Broken spirits: The treatment of traumatized asylum seekers, refugees, and war and torture victims. New York: Brunner-Routledge

[44] World Health Organization, (2011). Impact of economic crises on mental health: WHO Regional Office for Europe

[45] Yoshikawa, H., Aber, J. L. \& Beardslee, W. R. (2012). The effects of poverty on the mental, emotional and behavioral health of children and youth: Implications for prevention. American Psychologist Issue, 67(4), 272-284 